\title{
Relationships between Exercise as a Mood Regulation Strategy and Trait Emotional Intelligence
}

\author{
Dharmendra Solanki, MSc; Andrew M. Lane*, PhD
}

\author{
Authors' Affiliation: \\ University of Wolverhampton, \\ UK \\ * Corresponding Author: \\ Address: University of \\ Wolverhampton, UK \\ E-mail: a.m.lane2@wlv.ac.uk
}

Received: May 17, 2010

Accepted: Nov 01, 2010

Key Words: Self-regulation; Psychological skills; Well-being; Emotions; Mood

\begin{abstract}
Purpose: The aim of this study was to investigate the relationship between perception of emotional intelligence and beliefs in the extent to which exercising leads to mood-enhancement.

Methods: Volunteer participants $(N=315)$ completed a 33-item selfreport measure of trait emotional intelligence and an exercise-mood regulation scale.

Results: Emotional intelligence significantly correlated with beliefs that exercise could be used to regulate $\operatorname{mood}(r=0.45, P<0.01)$.

Conclusion: Findings demonstrate that using exercise to regulate mood relates significantly to emotional intelligence and suggest that individuals who use exercise to enhance mood report higher scores of emotional intelligence.
\end{abstract}

Asian Journal of Sports Medicine, Vol 1 (No 4), December 2010, Pages: 195-200

\section{INTRODUCTION}

$\mathrm{P}$ eople are proposed to monitor, evaluate, and employ several conscious and sub-conscious processes to regulate their moods ${ }^{[1]}$. Mood-regulation strategies are thoughts and behaviors intended to eliminate, maintain or change emotional states ${ }^{[1]}$. Most mood-regulating strategies focus on increasing or maintaining the intensity of positive mood states and decreasing or eliminating negative moods. Previous research has identified a range of behaviors that individuals use to regulate their moods including exercising, listening to music, seeking social support, engaging in positive self-talk, along with less socially desirable strategies such as drinking alcohol and smoking $^{[2]}$. Exercise has been demonstrated to be mood-enhancing repeatedly over a number of studies $^{[3]}$.

The notion that individuals can learn to use exercise as a strategy to help regulate mood states is founded on the belief that feelings are changeable. If people believe that emotions can change by exercising, for instance, they will invest efforts to implement emotion regulation strategies ${ }^{[4]}$. On the other hand, individuals who believe that emotions are fixed are less likely to engage in emotion regulation strategies.

Beliefs in the extent to which individuals can alter their emotional states can be assessed via self-report measures of emotional intelligence. However, considerable debate remains on the nature of emotional intelligence. A recent research has proposed that trait emotional intelligence refers to a constellation of 
emotion-related self-perceptions and dispositions located at the lower levels of personality hierarchies ${ }^{[5]}$. Trait emotional intelligence can be assessed through self-report scales such as the Emotional Intelligence Scale (EIS) ${ }^{[6]}$. The EIS has recently been validated for use in sport and exercise settings ${ }^{[7]}$ in a large scale study involving over 1500 athletes. Athletes who score high on the EIS have been found to use psychological skills frequently ${ }^{[8]}$ and be able to identify emotional states associated with optimal performance ${ }^{[9]}$. Therefore, there appears to be a growing body of intelligence in athletic settings.

The aim of this study was to investigate the relationship between trait emotional intelligence and beliefs in the effectiveness of exercise as a strategy to regulate mood. We hypothesized that high emotional intelligence would significantly relate to using exercise as a mood regulation strategy.

\section{METHODS AND SUBJECTS}

\section{Participants}

Volunteer participants $(N=315$; Mean age $=26.77, s=$ 5.49 years; 160 males and 155 females) were recruited from health and fitness clubs in the Birmingham area of the UK. Participants were heterogeneous in terms of their experiences of taking part in exercise. All participants reported to engage in exercise once a week, with considerable variation in the type and amount of completed exercise. Participants engaged in a range of different activities including treadmill walking, running, cardiovascular exercise on exercise machines, weight training and participation in different types of exercise classes including circuit training in yoga.

\section{Measures}

Exercise-Mood Regulation: Exercise-Mood Regulation Scale (EMRS) is a 28-item scale designed to assess beliefs in the effectiveness of using exercise as a mood regulating strategy. The scale was developed by revising the Music Mood Regulation Scale ${ }^{[10]}$. In the

present study "listening to music" has been changed to "taking part in exercise" for each item. The scale is based on the approach used by Thayer et $\mathrm{al}^{[1]}$ in their highly cited study in this area. A recently performed research has extended this research by focusing on the relative effectiveness of other commonly used mood regulation strategies such as listening to music ${ }^{[10]}$. The original scale was developed and validated to assess the effectiveness of music as a strategy to regulate mood. Adjectives to assess anger, depression, fatigue, tension and vigor were drawn from the Brunel Mood Scale (BRUMS) ${ }^{[11]}$ and adjectives to assess calmness and happiness subscales from the UWIST ${ }^{[12]}$. The confusion subscale was discarded from the BRUMS as it is proposed to be a cognitive rather than an affective state. Items are rated on a 5-point Likert scale ranging from 0 (not at all) to 4 (extremely). Examples of items include 'If you need to feel Restful, how effective is taking part in an exercise as a strategy to achieve this feeling' and 'If you need to feel Relaxed, how effective is taking part in an exercise as a strategy to achieve this feeling'. It should be noted that positive correlations should be found between the regulation of pleasant and unpleasant mood states as the response stem asks participants how effective exercise is at increasing positive and decreasing negative mood states. Preliminary results indicated significant correlations and alpha coefficient for a single-factor scale was 0.89 . A copy of the measure is contained in the Appendix and we invite researchers to use the scale.

Emotional Intelligence: The EIS is a commonly used self-report measure of emotional intelligence ${ }^{[6]}$. The EIS comprises items that assess the ability to 'appraise own emotions' (e.g., 'I am aware of my emotions as I experience them'), 'appraise others' emotions' (e.g., 'I know what other people are feeling just by looking at them'), 'regulate emotions' (e.g., 'I have control over my emotions'), 'utilize emotions' (e.g., 'When I am in a positive mood, solving problems is easy for me') and 'social skills' (e.g., 'I compliment others when they have done something well').

A recent study sought to validate the EIS for use in sport and exercise settings ${ }^{[13]}$. Given that research in sport and exercise settings often requires self-report measures to be brief (such as before competition or before exercise), Lane et $\mathrm{al}^{[13]}$ sought to produce a 
shortened scale resulting in a 19-item version of the scale ${ }^{[13]}$. The alpha coefficient in the present study was 0.85 , which indicates an internally reliable scale. Participants rate items on a 5-point scale anchored by strongly agre $e^{[1]}$ to strongly disagree $e^{[5]}$.

\section{Procedure}

Following institutional ethical approval, data were collected from two different health and fitness clubs in the West Midlands, UK. Participants completed the questionnaire in the social areas of the clubs and gave informed consent before completing self-report measures. No participant withdrew from the study.

\section{RESULTS}

Descriptive statistics for emotional intelligence and using exercise to regulate mood are contained in Fig. 1. Correlation results indicated that emotional intelligence related significantly $(r=0.45, P<0.01)$ to perceptions that exercise was an effective strategy to enhance mood.

\section{DISCUSSION}

The aim of the present study was to investigate relationships between emotional intelligence and beliefs in the effectiveness of exercise as a strategy to regulate mood. Results provided support for the hypothesis proposing that emotional intelligence relates significantly believing that exercise is an effective strategy to an enhanced mood. Indeed, obtained results are consistent with previous researches demonstrating the mood enhancing effects of exercise ${ }^{[3]}$, and the notion that individuals higher in self-report emotional intelligence report typically more positive $\operatorname{mood}^{[9]}$.

Furthermore, our findings are in accordance with a previous research demonstrating that emotional intelligence is associated with positive attitudes toward health-related behaviors such as stopping smoking ${ }^{[14]}$. Emotions are proposed to act as feedback to guide future behaviors ${ }^{[15]}$. Applying this model to exercise, the combination of previous emotional outcomes and current emotional states contributes to peoples' future emotional outcomes and their actions accordingly. Individuals who have previously experienced positive emotions following exercise are more likely to develop beliefs that exercise could be used as a strategy to enhance mood in the future. Furthermore, emotionally intelligent individuals should be more sensitive to the

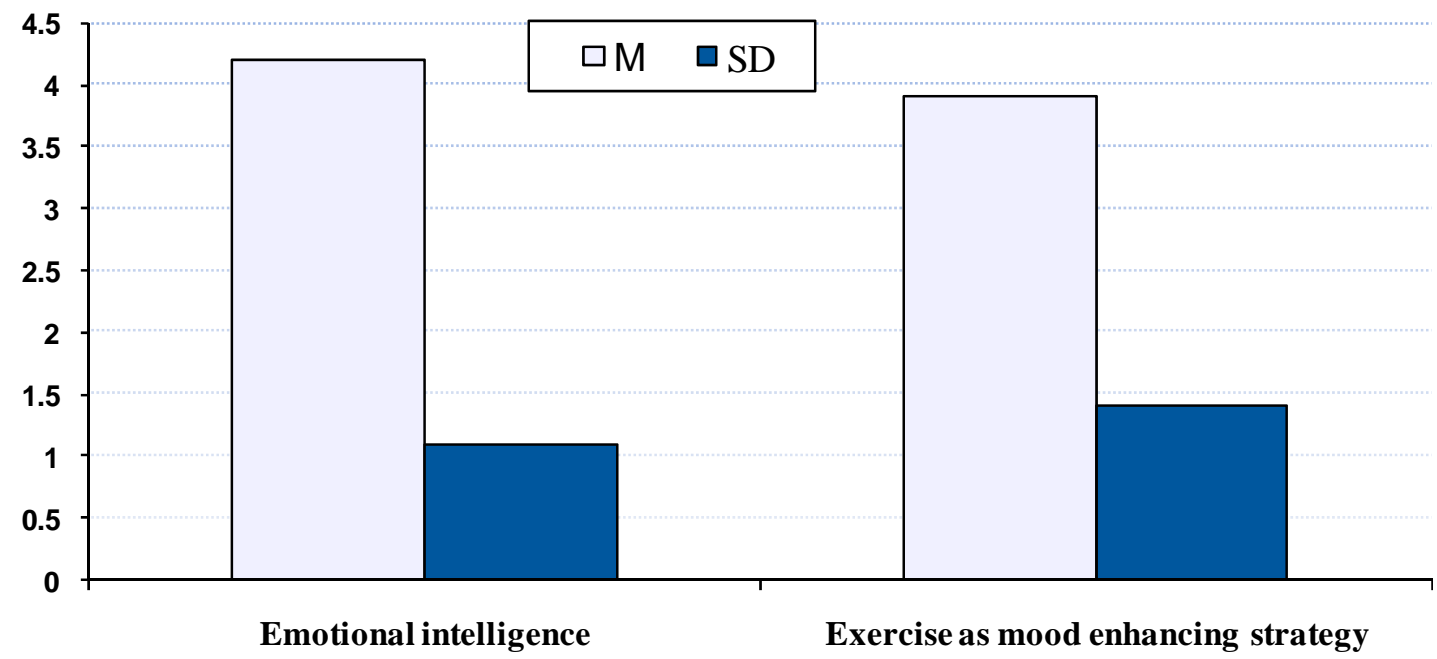

Fig. 1: Descriptive statistics mood regulation and emotional intelligence 
effects of exercise, and therefore should learn to associate exercise with mood enhancement more easily than their less emotionally intelligent counterparts. This proposal is contingent on individuals perceiving exercise to be mood enhancing.

Although research tends to show moodenhancement following exercise, this is not universally reported. In their extensive review of the salient exercise psychology literature, studies have emphasized that mood enhancement is dependent upon interactions between participant, exercise modality and

practice conditions; and made several recommendations for structuring an exercise session to maximize mood enhancement ${ }^{[3]}$. Mood enhancing activities should be non-competitive, rhythmic and predictable, should last for at least 20-30 minutes and should be moderately intense ${ }^{[3]}$. It is possible that individuals who engage in regular exercise may learn to derive positive mood benefits from exercise through experience, and that this process may influence beliefs about emotional intelligence. Previous research demonstrates that individuals derive greater mood enhancement when they engage in their preferred exercise modality ${ }^{[16]}$. An acknowledged limitation of the present study is that it was not possible to adequately control the type and intensity of exercise conducted by participants.

A limitation of the present study is the use of correlational research design. It is not possible to determine the direction of relationships between emotional intelligence and mood-regulation using exercise. It is feasible that emotions experienced during exercise raise awareness of emotions. This process could not only signal that emotions can be changed, but also provide the strategy on how to go about it. Future research should use an experimental design to answer the question on whether engaging in exercise leads to increases in emotional intelligence, or alternatively, whether emotionally intelligence helps individuals learn to enjoy participating in exercise.

\section{CONCLUSION}

In conclusion, results of the present study indicate that emotional intelligence correlate with beliefs in the effectiveness of exercise in enhancement of mood states. Future research should explore the direction of this correlation through experimental research design.

\section{ACKNOWLEDGMENTS}

We would like to thank the Institutional Review Board for granting permission to conduct this study and thank Dr Helen Lane for her comments on early versions of this paper.

Conflict of interests: There are no conflicts of interests.

\section{REFERENCES}

1. Parkinson B, Totterdell P, Briner RB, Reynolds S. Changing moods: The psychology of mood and mood regulation. London: Longman; 1996.

2. Thayer RE, Newman JR, McClain TM. Self-regulation of mood: Strategies for changing a bad mood, raising energy, and reducing tension. J Pers Social Psych. 1994;67:910-17.

3. Berger BG, Motl RW. Exercise and mood: a selective review and synthesis of research employing the Profile of Mood States. $J$ Applied Sport Psych. 2000;12:69-92.

4. John OP, Gross JJ. Individual differences in emotion regulation. 2007. 
5. Petrides K, Furnham A. Trait emotional intelligence: Behavioural validation in two studies of emotion recognition and reactivity to mood induction. Eur J Pers. 2003;17:39-57.

6. Schutte NS, Malouff JM, Hall LE, et al. Development and validation of a measure of emotional intelligence. Pers Individ Dif. 1998;25:167-77.

7. Lane AM, Thelwell R, Gill G, Weston N. Confirmatory factor analysis of the Emotional Intelligence Scale on an athletic sample. J Sports Sci. 2007;25:312.

8. Lane AM, Thelwell RC, Lowther J, Devonport TJ. Emotional intelligence and psychological skills use among athletes. Soc Behav Pers. 2009;37:195-201.

9. Lane AM, Thelwell R, Devonport TJ. Emotional intelligence and mood states associated with optimal performance. E J Applied Psychol. 2009;5:67-73.

10. Hewston RM, Lane AM, Karageorghis CI. Development and initial validation of an instrument to assess the perceived effectiveness of music as a strategy to regulate mood: The Music Mood-Regulation Scale. E J Applied Psychol. 2009;4:15-22.

11. Terry PC, Lane AM, Fogarty GJ. Construct validity of the Profile of Mood States - Adolescents for use with adults. Psychol Sport Exerc. 2003;4:125-39.

12. Matthews G, Jones DM, Chamberlain AG. Refining the measurement of mood: The UWIST Mood Adjective Checklist. Br $J$ Psychol. 1990;81:17-42.

13. Lane AM, Meyer BB, Devonport TJ, et al. Validity of the Emotional Intelligence Scale for use in Sport. J Sports Sci Med. 2009;8:289-95.

14. Schutte NS, Malouff JM, Thorsteinsson EB, Bhullar N, Rooke SE. A meta-analytic investigation of the relationship between emotional intelligence and health. Pers Individ Dif. 2007;42:921-33.

15. Baumeister RF, Vohs KD, DeWall CN, Zhang L. How emotion shapes behavior: Feedback, anticipation, and reflection, rather than direct causation. Pers Soci Psychol Rev. 2007;11:167-203.

16. Lane AM, Jackson A, Terry PC. Preferred modality influences on exercise-induced mood changes. J Sports Sci Med. 2005;4:195-200. 
Appendix: Exercise - mood regulation scale

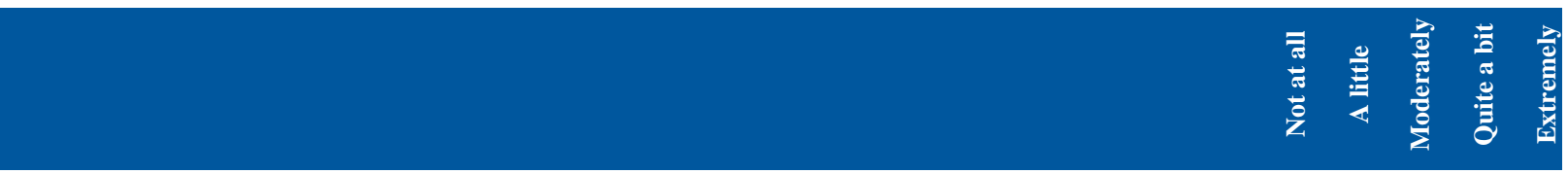

1. If you need to feel Restful, how effective is taking part in exercise as a strategy to achieve this feeling

2. If you need to feel Relaxed, how effective is taking part in exercise as a strategy to achieve this feeling

$\begin{array}{lllll}0 & 1 & 2 & 3 & 4\end{array}$

3. If you need to feel Lively, how effective is taking part in exercise as a strategy to achieve this feeling

$\begin{array}{lllll}0 & 1 & 2 & 3 & 4\end{array}$

4. If you need to feel Happy, how effective is taking part in exercise as a strategy to achieve this feeling

5. If you need to feel Energetic, how effective is taking part in exercise as a strategy to achieve this feeling

6. If you need to feel Contented, how effective is taking part in exercise as a strategy to achieve this feeling

7. If you need to feel Composed, how effective is taking part in exercise as a strategy to achieve this feeling

8. If you need to feel Cheerful, how effective is taking part in exercise as a strategy to achieve this feeling

9. If you need to feel Calm, how effective is taking part in exercise as a strategy to achieve this feeling

10. If you need to feel Alert, how effective is taking part in exercise as a strategy to achieve this feeling

11. If you need to feel Active, how effective is taking part in exercise as a strategy to achieve this feeling

12. If you need to feel Satisfied, how effective is taking part in exercise as a strategy to achieve this feeling

13. If you are feeling Worried, how effective is taking part in exercise as a strategy to change this feeling

14. If you are feeling Worn out, how effective is taking part in exercise as a strategy to change this feeling

15. If you are feeling Unhappy, how effective is taking part in exercise as a strategy to change this feeling

16. If you are feeling Tired, how effective is taking part in exercise as a strategy to change this feeling

17. If you are feeling Sleepy, how effective is taking part in exercise as a strategy to change this feeling

18. If you are feeling Panicky, how effective is taking part in exercise as a strategy to change this feeling

19. If you are feeling Nervous, how effective is taking part in exercise as a strategy to change this feeling

20. If you are feeling Miserable, how effective is taking part in exercise as a strategy to change this feeling

21. If you are feeling Exhausted, how effective is taking part in exercise as a strategy to change this feeling

22. If you are feeling Downhearted, how effective is taking part in exercise as a strategy to change this feeling

23. If you are feeling Depressed, how effective is taking part in exercise as a strategy to change this feeling

24. If you are feeling Bitter, how effective is taking part in exercise as a strategy to change this feeling

25. If you are feeling Bad tempered, how effective is taking part in exercise as a strategy to change this feeling

26. If you are feeling Anxious, how effective is taking part in exercise as a strategy to change this feeling

27. If you are feeling Annoyed, how effective is taking part in exercise as a strategy to change this feeling

28. If you are feeling Angry, how effective is taking part in exercise as a strategy to change this feeling

$\begin{array}{lllll}0 & 1 & 2 & 3 & 4\end{array}$

$\begin{array}{lllll}0 & 1 & 2 & 3 & 4\end{array}$

$\begin{array}{lllll}0 & 1 & 2 & 3 & 4\end{array}$

$\begin{array}{lllll}0 & 1 & 2 & 3 & 4\end{array}$

$\begin{array}{lllll}0 & 1 & 2 & 3 & 4\end{array}$

$\begin{array}{lllll}0 & 1 & 2 & 3 & 4\end{array}$

$\begin{array}{lllll}0 & 1 & 2 & 3 & 4\end{array}$

$\begin{array}{lllll}0 & 1 & 2 & 3 & 4\end{array}$

$\begin{array}{lllll}0 & 1 & 2 & 3 & 4\end{array}$

$\begin{array}{lllll}0 & 1 & 2 & 3 & 4\end{array}$

$\begin{array}{lllll}0 & 1 & 2 & 3 & 4\end{array}$

$\begin{array}{lllll}0 & 1 & 2 & 3 & 4\end{array}$

$\begin{array}{lllll}0 & 1 & 2 & 3 & 4\end{array}$

$\begin{array}{lllll}0 & 1 & 2 & 3 & 4\end{array}$

$\begin{array}{lllll}0 & 1 & 2 & 3 & 4\end{array}$

$\begin{array}{lllll}0 & 1 & 2 & 3 & 4\end{array}$

$\begin{array}{lllll}0 & 1 & 2 & 3 & 4\end{array}$

$\begin{array}{lllll}0 & 1 & 2 & 3 & 4\end{array}$

$\begin{array}{lllll}0 & 1 & 2 & 3 & 4\end{array}$

$\begin{array}{lllll}0 & 1 & 2 & 3 & 4\end{array}$

$\begin{array}{lllll}0 & 1 & 2 & 3 & 4\end{array}$

$\begin{array}{lllll}0 & 1 & 2 & 3 & 4\end{array}$

$\begin{array}{lllll}0 & 1 & 2 & 3 & 4\end{array}$

$\begin{array}{lllll}0 & 1 & 2 & 3 & 4\end{array}$

$\begin{array}{lllll}0 & 1 & 2 & 3 & 4\end{array}$

$\begin{array}{lllll}0 & 1 & 2 & 3 & 4\end{array}$ 